\title{
Intermittent irritability in a toddler
}

\author{
Susana Alexandre, ${ }^{1}$ Mafalda Castelão, ${ }^{2}$ Sara Santos, ${ }^{1}$ Pedro Fernandes ${ }^{3}$
}

'Paediatrics, Centro Hospitalar do Oeste, Caldas da Rainha, Portugal

${ }^{2}$ Paediatrics, Hospital de Santa Maria, Lisboa, Portugal

${ }^{3}$ Department of Orthopedics and Trauma, Hospital de Santa Maria, Lisboa, Portugal

\section{Correspondence to}

Dr Susana Alexandre; susanadalexandre@gmail.com

Accepted 11 May 2021

\section{DESCRIPTION}

We present the case of a healthy 15 -month-old boy, who presented to our emergency department with intermittent unspecified dorsal pain and periods of irritability for the last 2 weeks. During the last week, parents reported significant worsening of his general condition with episodes of polypnoea, nocturnal awakening and progressive gait refusal. Pain was relieved in supine position and responded well to ibuprofen. No other symptoms were reported except diarrhoea 2 weeks prior to the beginning of symptoms. A fall from height was reported 7 weeks prior to admission, resulting in a minor lip incision with spontaneous healing; no history of trauma involving the back or legs was found. No relevant epidemiological context or family history was identified. On admission, he looked prostrated, uncomfortable while sitting, referring no pain on palpation/percussion of the spine. Spinal flexion and extension were limited by pain with asymptomatic passive mobilisation of the lower limbs. He refused standing or walking due to pain. On admission, he was afebrile (tympanic temperature $36.8^{\circ} \mathrm{C}$ ), with a pulse of $132 \mathrm{bpm}$ and blood pressure $98 / 54 \mathrm{~mm}$

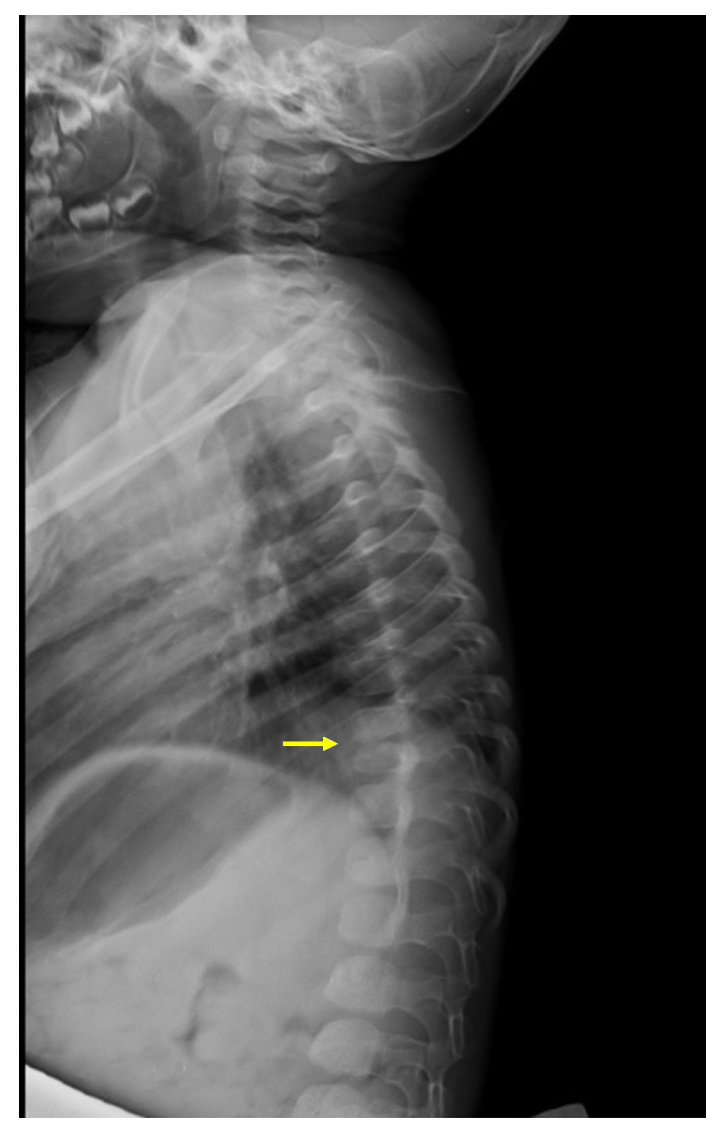

Figure 1 Vertebral X-ray, showing a decrease in disc height involving D9 and D10 vertebras (arrow).

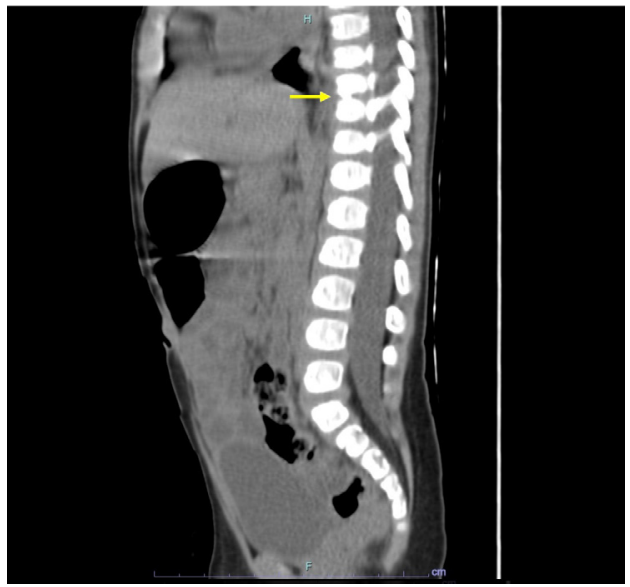

Figure 2 Vertebral CT, showing irregularity of D9-D10 vertebral bodies (arrow), with possible relation to bone destruction.

Hg. He started fever at the hospital that persisted for 2 days. Chest X-ray was normal but on lateral view, a decrease in disc height was evident on the low thoracic spine (figure 1). The blood panel revealed increased erythrocyte sedimentation rate $(55 \mathrm{~mm} /$ hour$)$ and alkaline phosphatase $(1076 \mathrm{U} / \mathrm{L})$, with normal $\mathrm{C}$ reactive protein and blood count. Spinal CT showed vertebral irregularity of D9-D10 with possible relation to bone peridiscal erosions suggesting spondylodiscitis (SD) (figure 2). MRI confirmed the diagnosis (figure 3). No agent was identified in microbiology and molecular studies. Mantoux test was not performed, but an Interferon Gamma Release Assays (IGRA) test for Mycobacterium tuberculosis was negative. Blood cultures for identification of Kingella kingae were also negative. After 8 days of intravenous ceftriaxone, he was asymptomatic and was discharged with oral amoxicillin and clavulanic acid for 5 weeks. No intercurrences or sequels were documented; at 2-year follow-up he had normal activity and X-ray showed a complete disc height restoration.

$\mathrm{SD}$ is a rare entity in paediatrics and diagnosis can be delayed because of low incidence and lack of awareness. In children, the incidence is about $0.3 / 100000 .{ }^{1} \mathrm{SD}$ is characterised by an inflammatory process involving the intervertebral disc and adjacent vertebral bodies, resulting in symptomatic narrowing of the intervertebral space. It typically occurs in children younger than 6 years, and the lumbar discs are most commonly affected, but any disc may be involved. ${ }^{2-4}$ In most patients, spinal seeding occurs haematogenously from a previously existing site of infection. Pathogens however, can be exceptionally inoculated from a diagnostic/surgical procedure and following trauma. ${ }^{2}$ In more than 


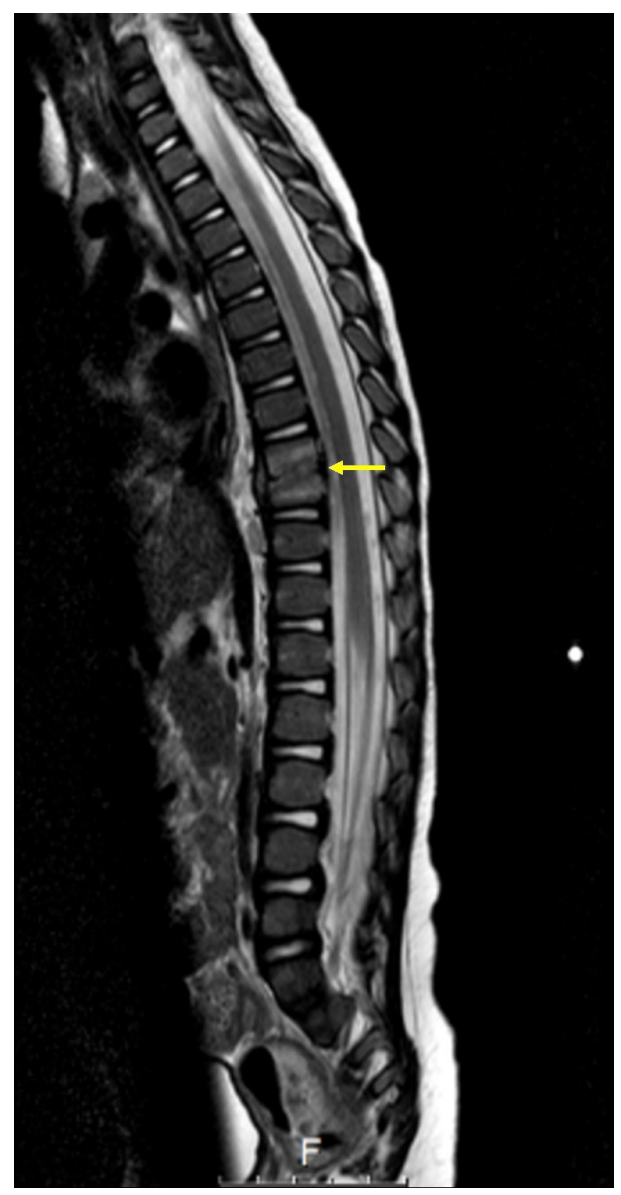

Figure 3 Vertebral MRI, with evidence of an inflammatory process involving D9 and D10 (arrow) with disruption of bone structure and intervertebral disc destruction.

half of the cases no micro-organism can be identified, but when isolated Staphylococcus aureus prevails. ${ }^{1-4}$ Clinical manifestations vary with age. It is not unusual for toddlers to present only with non-specific signs such as irritability, and not the classic low back pain and antalgic gait. ${ }^{3}$ This can explain why diagnosis of SD can be difficult, as little advantage is derived quite often from the use of laboratory tests and conventional radiography.

\section{Learning points}

- The beginning of symptoms in spondylodiscitis is usually insidious and physical examination is often poor, therefore, it can go unnoticed.

- The low specificity of symptoms, such as irritability and normal range laboratory data, the scarcity of physical examination findings and the late radiographic changes are responsible for the usual late diagnosis of this disease, which depends largely on the clinician's suspicion.

- Staphylococcus aureus is still the most common isolated agent, although in the majority of reported cases no agent is identified.

A delay in establishing the diagnosis has been found, with studies reporting an average of 27 days going up to between 4 and 6 months. ${ }^{4}$ MRI is highly sensitive for an early diagnosis and tandem to clinical evaluation, an excellent examination for monitoring disease progression. Treatment includes rest, nonsteroidal anti-inflammatory drugs, antibiotics, casting in some patients and physiotherapy if appropriate. Prognosis is generally good, especially with early diagnosis and adequate therapy followed by close clinical follow-up. ${ }^{23}$

\section{Acknowledgements Ana Mouzinho.}

Contributors Identified and managed the case: SS, PF. Performed the literature search: SA, MC. Wrote the article: SA. Reviewed the article: PF, MC, SS

Funding The authors have not declared a specific grant for this research from any funding agency in the public, commercial or not-for-profit sectors.

Competing interests None declared.

Patient consent for publication Parental/guardian consent obtained.

Provenance and peer review Not commissioned; externally peer reviewed.

\section{REFERENCES}

1 Kang HM, Choi EH, Lee HJ, et al. The etiology, clinical presentation and long-term outcome of spondylodiscitis in children. Pediatr Infect Dis J 2016;35:e102-6.

2 Principi N, Esposito S. Infectious discitis and spondylodiscitis in children. Int J Mol Sci 2016;17:539.

3 Gamero DB, Tomé MI, Conejo PR. Discitis o espondilodiscitis. In: SEIP-AEP. Protocolos diagnóstico-terapéuticos de Infectología. 3 edn. Madrid: ERGON, 2011: 9-12.

4 Dayer R, Alzahrani MM, Saran N, et al. Spinal infections in children: a multicentre retrospective study. Bone Joint J 2018;100-B:542-8.

Copyright 2021 BMJ Publishing Group. All rights reserved. For permission to reuse any of this content visit

https://www.bmj.com/company/products-services/rights-and-licensing/permissions/

BMJ Case Report Fellows may re-use this article for personal use and teaching without any further permission.

Become a Fellow of BMJ Case Reports today and you can:

- Submit as many cases as you like

- Enjoy fast sympathetic peer review and rapid publication of accepted articles

- Access all the published articles

Re-use any of the published material for personal use and teaching without further permission

Customer Service

If you have any further queries about your subscription, please contact our customer services team on +44 (0) 2071111105 or via email at support@bmj.com.

Visit casereports.bmj.com for more articles like this and to become a Fellow 